Session 2793

\title{
Integrating Business Concepts into ECE Design Courses: An Alternate Approach
}

\author{
Henry Chaya, FSC, Associate Professor \\ Gordon Silverman, Professor \\ Electrical and Computer Engineering \\ Manhattan College, Riverdale, New York
}

\begin{abstract}
To prepare students for the 21 st century global environment, Consultor groups and ABET have encouraged engineering schools to make provision for leadership development within their programs. The model envisioned by the corporate/industrial community would aim to have students achieve competency in business practices equivalent to the proficiencies realized in engineering subject areas. One method for achieving this is to ask students to respond to "Request for Proposal" (RFPs) in which inter- and multi-discipline design teams "compete" with alternate solutions. Corporate representatives provide realistic scenarios through active participation in such courses. These "clients" require the students to use realistic project management tools and reinforce planning and economic aspects of a design without neglecting the technical aspects of the project. While such approaches have proven successful, they neglect an important element of leadership development - the "entrepreneurial" aspect. To this end, we describe an alternative scenario that we have designated the "venture capital" (VC) approach. It retains the important feature in which corporate representation is retained but requires students to initiate their own projects (as opposed to providing an RFP). Class discussions provide information for development of a Business Plan including: purpose, use of tile technology, market analysis and forecast, financial plan, and management. Student projects are depicted and include: Voice biometrics wherein an individual's speech pattern is digitized and stored to produce a "voiceprint"; an electronic tuner for selecting signals at specific frequencies and sound reproduction; an electronic audiometer for testing hearing loss. Course assessment results and evaluation are explained.

I. Background

The industrial and corporate roles that engineering graduates play have greatly broadened as a consequence of the emergence of the "global" character of economic activity. Accordingly, objectives for engineering design has shifted from those characterized mainly by practical consideration (e.g., component, system, or process design) to those embracing the integration of business and entrepreneurial skills coupled with technical skills. Team-oriented design, and awareness of the economic, reliability, and social impact of work product are a few of the new educational prerequisites for this climate. This redirection follows from outcomes assessments and needs of the engineering industrial/corporate client community and subsequently from ABET. As noted in the Criteria for Accrediting Engineering Programs [1],
\end{abstract}


"Students must be prepared for engineering practice through the curriculum culminating in a major design experience based on the knowledge and skills required in earlier course work and incorporating engineering standards and realistic constraints that include most of the following considerations: economic; environmental; sustainability; manufacturability; ethical; health and safety; social; and political." [Emphasis added.]

At Manhattan College - as in many engineering institutions - each department in the School of Engineering relies on a group of "Consultors" as part of its assessment program. These professionally successful individuals assist the School of Engineering (SOE) in the planning and direction of its various programs. As part of this counsel the Department of Electrical and Computer Engineering (ECE) engaged the Consultors in dialog on the question "What should Manhattan College School of Engineering look like in the $21^{\text {st }}$ Century, and what actions are needed to achieve that vision?" [2] A consensus among Consultors is that engineering leaders today need competency in specific areas that are often part of a business or liberal program of study, such as economics, accounting, operations management, and law. Additionally, engineering leaders need competency in many "soft" skills such as non-linear "out-of-the-box" thinking, collaboration and team building, and effective communications that are normally not encountered in a particular field of study (at least at the undergraduate level). Based on this consensus, the Consultors offered recommendations to strengthen the existing ECE program: ${ }^{1}$

- add subject matter to stimulate development of leadership skills in addition to engineering proficiency;

- introduce integrated Engineering and Business programs;

- reinforce collaboration with industry.

Within the educational community, some institutions have responded with comprehensive academic programs in Entrepreneurial Engineering. [3,4] Such programs include several "entrepreneurial" goals: readiness for professional opportunities in growth-oriented environments or self-employment, develop enhanced communication skills, understand sound marketing and financial plans, preparation for management and team leadership positions.

Such curricula severely impact the traditional engineering programs and are not well suited to many, modestly-sized, institutions that must try to prepare students for professional opportunities as either project engineers, traditional research and design engineers, or for advanced study (i.e., Ph.D.).

\section{The RFP Approach to Capstone Design}

With the trends in "entrepreneurial" engineering gleaned from the Consultor recommendations, tendencies within the industrial/corporate community, and guidance from ABET, the SOE as well as the ECE department embarked on curricula support for educational experiences critical to leadership within the profession. Two examples will illustrate potential alternatives:

\footnotetext{
${ }^{1}$ Only those recommendations that are pertinent to the advancement of "entrepreneurial" educational objectives have been cited. 
Environmental Engineering: At Manhattan College a major design experience (with "entrepreneurial" overtones) occurs in the Department of Environmental Engineering with the introduction of the capstone design course entitled, "The Company." It is an open-ended project based course where students work on specific, real-world problems. It spans two semesters and is conducted in a consulting/industrial firm format with students working in groups of four to six with a faculty member and one or more outside professionals. Students apply their basic knowledge of science and engineering to new and open-ended problems; they are encouraged to develop creative solutions to environmental engineering problems. Communication skills are enhanced through preparation of proposals, reports and formal presentations; time management skills and teamwork skills prepare the student for the workplace.

Within ECE: To meet these educational objectives, add an "entrepreneurial" component, and to retain important elements of a "traditional" capstone design course, Manhattan College introduced an interdisciplinary design course that was augmented by participation of a number of alumni with considerable engineering experience. [5] ECE and Mechanical engineering majors were asked to design, build and test a robotic manipulator system to determine the edges of an arbitrary, flat, two-dimensional object. The system had to automatically locate the edges of the object and display the contour as a graphic on a computer monitor; a two-axis manipulator had to retrace the contour with a specified accuracy and speed. (The device would be suitable for cutting a variety of materials (e.g., fabric or sheet metal).) In essence, the students were provided with a set of specifications that they were required to address. The engineering alumni assisted by playing the role of clients, thereby providing a practical flavor for the course. They could raise questions about project schedules, reports and presentations, as is done for their own clients. Thus, the students received experience in contemporary interdisciplinary design environments with awareness of the economic, social and ethical realities that constrain an engineering project. While the program had considerable success, it did not address specific needs that support growing opportunities within small firms that are centered on more entrepreneurial and innovative behaviors.

\section{The Entrepreneurial Approach to ECE Capstone Design Courses.}

Both of the examples cited above started from project specifications to which the students were required to respond. In doing so they developed some entrepreneurial experience: enhancement of communication skills, time management, an awareness of marketing, team-oriented project management and economic implications of engineering design and development. While these characteristics are important, they lack critical aspects of entrepreneurial enterprise - in particular, the "innovative spark," and awareness of risks/rewards associated with novelty. Recently, the ECE department restructured the capstone design experience with the focus shifted to student initiated innovative projects while retaining those positive aspects that such courses have previously delivered (e.g., team-oriented design, etc.). Student-teams were instructed to develop projects for funding by a group of "venture capitalists" (VC). (The VCs included faculty members as well as a representative from the corporate community.) Faculty participants provided lectures on development of sound Business Plans. Elements of this material included: 
- Nature of a Business Plan: intended to promote investment in an enterprise with the expectation of providing revenue or other considerations at some specified time(s) with profitability as its goal.

- Investor role: provide assets enabling the enterprise to develop a product or service.

- Role of the Directors: agree to share ownership; provide a revenue stream to the investor.

- Organization of the Business Plan: Executive Summary; Description of the business; Description and use of the technology; Market analysis and forecasts; Financial plan; Management Structure.

\section{Assessment}

The course was intended to achieve a number of outcomes with a high measure of applicability to the engineering curriculum. Examples of these include enhancing the student's ability in a number of professional activities: to use computers in solving engineering problems; to think critically in analyzing engineering problems; to solve open-ended engineering design problems; to function on multi-disciplinary teams; to communicate effectively. All of these outcomes achieved success ratings of $90 \%$ (or better) using several metrics; student work product evaluated by faculty and the VCs and a student survey. Typical of the critique provided by the $\mathrm{VCs}$ is reflected in the following comment regarding a team submission:

"In this section I would provide more detail on the developmental status of the product. If a prototype is complete, has it been tested? What else is required to make the product ready for mass production at the appropriate quality \& industry standards? What industry-specified tests have been or will be done? Have you investigated if your design infringes on existing patents (which means you have to pay royalties) or if you can file one if you feel your design is unique enough?"

Among the recommendations of the faculty leader was the requirement to create a better balance between the business and technical aspects of the course, and the need to adjust the course meeting times to schedule a two-hour time slot to provide a sustained period for team meetings and design activities.

\section{Results and Discussion}

Three Computer Engineering student teams were formed into "corporate entities" and each group was required to develop a product that would interest the VCs. (Each team consisted of five students.) To retain the technical elements of the design course, the teams were expected to produce a working model of their project by the end of the semester. One technological constraint required the students to use the Xilinx (Complex Programmable Logic Devices, CPLD) in their projects. This provided an avenue for exploitation of this advanced technology; familiarity with the Xilinx system was developed during the first semester of the year-long design course sequence. The three products are summarized below: 
Hearing Tester: A series of "pure tones" are developed in the CPLD and presented to a subject. The frequencies ranged from $20 \mathrm{~Hz}$ to $20,000 \mathrm{~Hz}$ which parallels those of commercial testers. The tone intensity is varied and the subject is asked to respond when he or she detects its presence. System timing cycled the intensity such that an intensity of $10 \mathrm{db}$ was achieved in 10 seconds; this was the "hearing threshold" for the tone under test. The system was designed to find hearing thresholds for all a series of tones in the spectrum, chart them, and compare the results to "ideal" hearing thresholds. (An upward deviation of more than $10 \mathrm{db}$ from the ideal threshold was indicative of hearing loss.) Database information to be supplied to the system included subject age (as it affect hearing capability). Additionally, provision for subject (key) response signaled detection of the tone. The corporation ("Here \& Hearing, Inc.") sought $\$ 1.15$ million from the $\mathrm{VCs}$, expected the unit to retail for approximately $\$ 400$, and expected profits of $\$ 4.4$ million in year 3 of the business cycle. The team provided typical elements of a business plan: Description and Use of the Technology, Market Analysis \& Forecast, a Financial Plan and Organization (Management responsibilities) of the corporation. [6]

Voice Recognition: This endeavor was centered on Biometrics, and voice recognition in particular. As described by the design team ("Biovoice Technologies, Inc."), an individual's speech pattern is digitized and stored - the "voiceprint." The voiceprint is accessed each time that an individual attempts to access a "secure area" and compared against the incoming sample. The underlying basis for the comparison is the vocal tract shape of the speaker including: the position and movement of the glottal tissues, lips, jaw and tongue which correspond to speech movements in the vocal tract. The vocal tract modifies the spectral content of an acoustic wave as it passes through it, resulting in common speech. The system was designed to make use of features derived only from the vocal tract. The system was to include multi-level security (both normal PIN and voice authentication). In addition to the formal elements of the Business Plan (as outlined at the start of the semester by the faculty), team research took into account the need for compliance with FCC regulations. A comprehensive market analysis supported viability of this product line with an estimate market of $\$ 200$ million by 2005 . The team sought $\$ 300,000$ in equity capital from the VCs. [7]

Guitar Tuner: After noting that many electrical tuning devices rely on a needle-based (VU meter) with attendant limitations in precision, the team proposed to develop a digital system. The system was designed to digitize sound from a guitar - as representative of the initial product line - and compare the digitized frequency against the accepted value for the particular tone. A display would indicate whether the note was flat, sharp, or "in tune" using an LED-based component. (The team included a member familiar with music and the guitar in particular.) The team correctly identified a (major) technological barrier to success, namely the potential for "dither" in the display (wherein the indicator would vary throughout the entire display range (sharp, in-tune, flat). The system employed an on-board codec (incorporated into the Xilinx Xtend board) to accept the analog signal from the microphone transducer. The system settled on standard frequency values for each of the guitar strings (e.g., $440 \mathrm{~Hz}$ for the "concert A"). Further, the indicator would signal the extent of the "flatness" or "sharpness" by moving a display icon (bar) further from a desired center position. A variety of additional features was proposed: display of the note currently being tuned; audio output so that the user could hear the standard to which the note was being tuned. The development team sought $\$ 5$ million over a five year business cycle, projected the break-even point to be reached during the third year and sales 
to reach (approximately) $\$ 1.7$ million after three years with a target price between $\$ 500$ and $\$ 1,000$ (depending on features).[8]

\section{Conclusions}

To meet emerging "global engineering cultures" that needs to be addressed in a contemporary engineering curriculum, a relatively standard capstone design course was enhanced with the introduction of a "venture capital" format. The design course retained a number of important features of traditional capstone endeavors and, in addition students were asked to develop a technical product whose marketability was to be defended before a group of "venture capitalists." The experiment enabled the students to gain exposure to business concepts not normally a part of the traditional engineering curriculum. The students gained an appreciation of such entrepreneurial business concepts as equity, shares, profitability, return on investment, and business cycle among others. On a practical level, some limitations were identified during the assessment phase of the experiment. In particular, although students were questioned during presentation events by the VCs regarding certain (professional component) aspects of their designs (e.g., drafting of detailed specifications, engineering standards, manufacturability, ethical, health, safety and political considerations), the teams did not explicitly make provision for these components in their (written and oral) work product.

In addition, the teams undertook very ambitious technical projects and given the need to develop additional skills with the (state-of-the-art) Xilinx technology together with the need to explore business concepts with which the students were unfamiliar, the ultimate systems did not fully meet the designs specified in the initial proposals.

We do not consider these limitations to be insurmountable with regard to delivering a course in which entrepreneurial engineering is a prominent feature. Using the format outlined above, we are able to satisfy the requirements of a design course while addressing the emerging curriculum needs for global business cultures without stressing institutional resources.

\section{References:}

[1] Engineering Accreditation Commission, Criteria for Accrediting Engineering Programs, Effective for Evaluations During the 2001-2002 Accreditation Cycle, Accreditation Board for Engineering and Technology, Baltimore, MD

[2] Browne, et. al., ECE Conultors' Recommendations, Private communication and report for the ECE Department, 2002.

[3] Rizk, T., Howell, S., Riedel, C., Shamamy, P., Annegerg, L., Feierfeil, G., The Engineering Entrepreneurial Program at Lawrence Technological University, Proceedings of the 2002 ASEE/SEFI/TUB Colloquium, Berlin, Germany, Oct., 2002.

[4] Garcia, A., Estrada, C., Innovative and Entrepreneurial Approach in Chemical Engineering Education, Universidad Autonomica de Yucatan Mexico, www.iamot.org/paperarchive/142D.PDF.

[5] Chaya, H., Walker, G., A "real-life" interdisciplinary capstone design course, Proceedings of the 2001 American Society for Engineering Education Annual Conference \& Exposition, Charlotte, NC, 2001. 
[6] Becker, R., Erickson, G., Zannelli, G., Sliger, S, Mangalath, M., The Hearing Tester. Design Proposal for the Senior Design Course in Computer Engineering, Spring 2002.

[7] Tatta, J., Burke, N., Savino, J., Miranda, F., Smith, P. VoicePrint System, Design Proposal for the Senior Design Course in Computer Engineering, Spring 2002.

[8] Cruz, M., Engheben, D., Koshy, S., John, S., Stefanko, W., Guitar Tuner, Design Proposal for the Senior Desing Course in Computer Engineering, Spring 2002.

HENRY CHAYA

Brother Henry Chaya is Associate Professor of Electrical and Computer Engineering. His professional interests include robotics and automation, artificial intelligence, embedded control and digital systems design. He has contributed extensively to the development of laboratory courses including design of hardware and software. Dr. Chaya has taught an introductory programming course for several years and was recently Chair of the department. He earned a BS degree at Manhattan College (1973) and a Ph.D. at Princeton University (1981). Dr. Chaya is a member of the Brothers of the Christian Schools.

\section{GORDON SILVERMAN}

Professor of Electrical and Computer Engineering and current Chair of the ECE department. Dr. Silverman has over 45 years of broad engineering experience in industry, research and academia (including Biomedicine and its related sub-disciplines). He has authored four engineering titles, numerous papers and holds several patents. His current interest is focused on Telemedicine which aims to extend health care to those who would not otherwise have access. 